\title{
Reflexões iniciais sobre as diversas narrativas de uma história da filosofia
}

Gustavo Barreto Vilhena de Paiva

Doutorando em Filosofia pela USP

Resumo: Discuto aqui a necessidade de se estabelecer uma história da filosofia que recorra unicamente ao estudo de documentos de interesse filosófico, caso essa história nos deva ser útil para a compreensão de determinadas noções filosóficas a partir de seu desenvolvimento histórico. Para tanto, mostro primeiramente que, no momento em que uma narrativa histórica pressupõe um nível lógico além do seu nível documental, ela perde essa sua utilidade. Em seguida, aponto a maneira pela qual podemos narrar uma história da filosofia exclusivamente documental.

Palavras-chave: História da filosofia; narrativa; influência; texto; evento histórico.
Abstract: Here I discuss the necessity of establishing a history of philosophy which resorts only to the study of documents of philosophical interest, if this history is supposed to be useful for our understanding certain philosophical notions according to their historical development. To do so, I first show that in the very moment in which a historical narrative presupposes a logical level besides its documental level, it loses its usefulness. After that, I point out the way in which we can narrate an exclusively documental history of philosophy.

Keywords: History of philosophy; narrative; influence; text; historical event.

L'bistorien qui a reçu une formation pbilosopbique doit craindre de trop unifier, de systématiser, il faut qu'il laisse voir la diversité rebele. ${ }^{* 1}$ Paul Vignaux - Pars destruens

\footnotetext{
* Agradeço ao prof. José Carlos Estêvão (USP), sob cuja orientação venho desenvolvendo meu doutorado, e à CAPES, pelo financiamento da minha pesquisa.

1. VIGNAUX, P. Pbilosopbie au Moyen Age. Albeuve: Castella, 1987, p. 64.
} 
Em um determinado ponto do seu Pbilosopby and the Mirror of Nature, ainda no início do livro, Richard Rorty vê a necessidade de esclarecer o chamado 'problema mente-corpo' (mind-body problem). De acordo com ele, para compreender a construção desse problema de nada serve dissolvê-lo analiticamente, de maneira que só há uma opção para o filósofo que pretenda a ele escapar: compreender a sua história. Logo em seguida, essa história do 'problema mente-corpo' se torna a história da própria noção de 'mente' ${ }^{2}$. Assim, ao estabelecer o caminho a ser seguido para se chegar a uma melhor compreensão dessa noção, Rorty considera que analisar o termo 'mente' não o explica, pois a única maneira de compreendê-lo é pela narrativa de uma história da concepção de 'mente' que se desdobra, em seu livro, na descrição da maneira pela qual vários autores entenderam essa mesma noção. Ao optar pela história como explicação filosófica de um conceito em detrimento da análise, Rorty adere a uma concepção de filosofia que já vinha sendo elaborada havia anos - em particular, nas discussões sobre filosofia da ciência. Nesse campo, cada vez mais se tornava patente uma recusa da distinção entre a fundamentação lógica de uma teoria e a narrativa histórica da sua gênese. Antes tida como fundamental, essa distinção encontrou uma forte oposição nas obras seminais de Thomas Kuhn ${ }^{3}$ ou Paul Feyerabend ${ }^{4}$ e se vê totalmente superada na fórmula de Imre Lakatos: "filosofia da ciência sem história da ciência é vazia; história da ciência sem filosofia da ciência é cega"t. Nesse ponto, a fundamentação lógica de uma teoria só ganha significado quando inserida em uma narrativa histórica da gênese dessa teoria, de maneira que a filosofia da ciência e a história da ciência se confundem. Com efeito, se acompanharmos Rorty, filosofia e história da filosofia se confundem. O grande problema está na pergunta: de que história estamos falando aqui?

2. RORTY, R. Pbilosopby and the Mirror of Nature. 2nd ed. Princeton: Princeton University Press, 2009 (1979), pp. 32-8.

3. KUHN, T. S. The structure of scientific revolutions. 4 th ed. Chicago: The University of Chicago Press, 2012 (1962).

4. FEYERABEND, P. Against method. 4th ed. London-New York: Verso, 2010 (1975).

5. LAKATOS, I. "History of science and its rational reconstructions". PSA: Proceedings of the Biennal Meeting of the Philosopby of Science Association (1970), p. 91: "Philosophy of science without history of science is empty; history of science without philosophy of science is blind". 
Comecemos pela consideração da utilidade de uma tal história: qual é o seu objetivo? Se seguirmos os autores que vimos até agora, essa história parece nos servir para explicar teorias. Assim, se queremos saber o que é o heliocentrismo, fazemos a história do seu desenvolvimento desde os seus primeiros defensores gregos (como faz Pierre Duhem $^{6}$ ), passando pela adoção geral do geocentrismo e atingindo os grandes debates dos séculos XVI e XVII (as discussões que, de fato, animam os livros de Kuhn e Feyerabend supracitados). Porém, se prestarmos atenção, é possível ser ainda mais preciso do que fomos aqui. Com efeito, se pensarmos bem, notamos que Rorty não está preocupado exatamente com o estudo de toda uma teoria, mas somente com a compreensão de uma única noção - no caso dele, a noção de 'mente'. Para elucidá-la, podemos seguir um caminho histórico semelhante àquele citado há pouco, destacando as principais discussões em que a noção de 'mente' esteve em jogo (atentando, por exemplo, também para as diversas traduções que o termo ganhou no decorrer dos debates filosóficos) e, assim, finalmente, compreender com que sentido essa concepção chegou a um determinado período visado - no caso de Rorty, o nosso próprio. Pois bem, temos aqui clara a utilidade mais imediata dessa nossa história, a saber, ela deve explicar o significado de uma noção a partir da narrativa do desenvolvimento histórico dessa noção cuja compreensão pretendemos alcançar. Como vemos, a nossa história tem um objetivo claro: esclarecer aquelas noções que visamos compreender. E, no entanto, isso ainda não responde a nossa pergunta.

A mera declaração da utilidade que atribuímos à história da filosofia não basta para explicitar o tipo de história a que nos referimos, porque a explicação do objetivo da narrativa histórica (nesse caso, o esclarecimento de certas noções) não é ainda uma descrição do que seria essa narrativa histórica. Porém, nós já temos uma pista: se pretendemos explicar determinadas noções historicamente, deveremos adotar uma narrativa histórica que nos seja útil para atingir esse nosso objetivo. Eé justamente aqui que começam os problemas, pois parece haver duas maneiras de narrar a história de uma noção qualquer e, muitas vezes, ambas surgem mescladas. Uma primeira possibilidade é a elaboração de uma narrativa histórica que se dá, de fato, em um

6. DUHEM, P. Sauver les apparences: sur la notion de théorie physique de Platon à Galilée. 2e éd. Paris: Vrin, 2003 (1908). 
nível puramente lógico, uma vez que, nela, a remissão a textos ou autores individuais é meramente acessória. Um exemplo muito claro desse tipo de narrativa histórica pode ser encontrado em Le point de départ de la métaphysique, de Joseph Maréchal, quando, em certo momento, ele nota que talvez "não seja supérfluo lembrar ao leitor que os itinerários traçados neste Caderno, de sistema em sistema, são antes de tudo itinerários lógicos: se eles respeitam a sucessão temporal, eles não traduzem necessariamente dependências literárias"' Como se vê, o itinerário seguido por Maréchal em seu curso sobre metafísica é, antes de tudo, lógico e as remissões aos autores individuais que compõem a história narrada não têm nenhum comprometimento com alguma relação palpável que se possa estabelecer entre os autores comparados. Assim, a história de Maréchal se reduz a uma sucessão cronológica na qual os atores respeitam um itinerário lógico pré-estabelecido, não cabendo a eles qualquer participação na elaboração do caminho que trilham. Agora, Maréchal só está em posição de propor uma história tão esvaziada porque ela, de fato, não é, para ele, senão um método de exposição de uma tese já estabelecida. Em outras palavras, Maréchal não busca construir sua tese filosófica com base na história narrada; antes, essa história meramente expõe de maneira palatável uma tese filosófica pré-concebida. Ele nos diz, "não fazemos trabalho de historiador. Uma história integral e exaustiva - supondo mesmo que nós teríamos a competência de escrevê-la - apresentaria sinuosidades demais para que pudesse servir utilmente como ilustração da nossa demonstração teórica, pois o movimento concreto das ideias, se ele obedece no conjunto ao impulso regular de algumas correntes principais, escapa sempre, ao largo, em desvios e recomeços" ${ }^{\prime \prime}$. Como

7. MARÉCHAL, J. Le point de départ de la métaphysique: leçons sur le développement bistorique et théorique du problème de la connaissance. Cahier I. De l'Antiquité à la fin du Moyen Age: La Critique Ancienne de la Connaissance. 2e éd. Bruges: Charles Beyart, 1927, p. 94: "Peut-être ne sera-t-il pas superflu de rappeler au lecteur que les itinéraires tracés, dans ce Cahier, de système à système, sont avant tout des itinéraires logiques: s'ils respectent la succession temporelle des doctrines, ils ne traduisent pas nécessairement des dépendances littéraires".

8. Idem, p. 6: "Nous ne faisont pas oeuvre d'historien. Une histoire intégrale et exhaustive - à supposer même que nous ayons la compétence pour l'écrire - présenterait trop de sinuosités pour servir utilement d'illustration à notre démonstration théorique: car le mouvement concret des idées, s'il obéit pour 
se vê, quando acreditamos partir de uma demonstração teórica produzida em um nível lógico superior e anterior à própria história, esta última, se for desenvolvida em seus mínimos detalhes, pode chegar até mesmo a atrapalhar a exposição da demonstração, uma vez que nos desviaria para as minúcias do desenvolvimento histórico dos temas estudados.

O curioso é que, ao que parece, a mesma história que possibilitaria para Rorty o esclarecimento da noção de 'mente' corria o risco de atrapalhar Maréchal em sua exposição filosófica - como isso é possível? A resposta está no fato de que eles não estão fazendo história de uma mesma maneira. Com efeito, se atentarmos para a última passagem citada de Maréchal, ele nos diz que a história só é útil como ilustração de uma demonstração teórica. Ou seja, a história só é útil na medida em que distinguimos cuidadosamente o plano da narrativa histórica daquele outro plano da demonstração lógica ${ }_{i}$ o primeiro pode até servir para ilustrar o segundo, mas ambos não devem ser confundidos. Como vimos acima, Rorty, ao contrário, já está no limiar do ultrapassamento dessa distinção e, para ele, o esclarecimento lógico de uma noção só pode ser compreendido quando esta última é inserida em um contexto histórico. Ou seja, se temos por objetivo compreender um conceito a partir da sua história, certamente não podemos nos valer de uma história ao modo de Maréchal, pois esta última já pressuporia a determinação lógica do conceito enquanto que, para nós, essa determinação só pode ser estabelecida na própria história. Mas, se era dito acima que parece haver duas maneiras de se fazer história, tendo excluído essa história que pressupõe um itinerário lógico, resta que façamos uma história na qual a explicação do conceito se torne patente pelo próprio desenvolvimento histórico narrado, sem qualquer recurso a um pretenso plano lógico anterior à própria história. Mas, como seria uma história desse tipo?

A grande dificuldade aqui é que este último tipo de história não parece ter sido claramente descrito. Porém, há pouco era dito que há certas narrativas que parecem mesclar essa duas concepções de história que estamos estudando e, para tanto, elas pretendem trabalhar, ao mesmo tempo, em dois níveis de narrativa: um lógico (ou seja, puramente lógico) e outro que denominarei 'documental', uma vez que se

l'ensemble à l'entraînement régulier de quelques courant principaux, s'échappe toujours, à côté, en détours et en recommencements". 
volta muito diligentemente para os documentos que dizem respeito à história da filosofia, a saber, os textos de interesse filosófico9. Um exemplo claro desse tipo de mescla é Étienne Gilson, por exemplo, no seu The unity of pbilosopbical experience. Nesse conjunto de conferências, Gilson inicia a discussão sobre o que ele denomina de 'projeto cartesiano' (Cartesian project), de maneira bem impactante, ao citar Eaton, quando este último afirma que "René Descartes, mais do que qualquer outra figura no século XVII, marca a transição da Idade Média para o mundo moderno"10. Logo após citá-lo, Gilson se apressa a dizer que "ainda que seja um lugar comum, essa afirmação possui um núcleo sólido de verdade histórica"11. Ainda assim, não precisamos seguir muito adiante a leitura para notarmos que Gilson não aceita a fórmula de Eaton senão com certas 'qualificações', como ele as chama. A primeira qualificação é que "Descartes marca a transição mais do Renascimento, do que da Idade Média, para o mundo moderno". A segunda qualificação é que, para ser ainda mais preciso, é necessário dizer que "ele nem mesmo marca a transição de todo o Renascimento para o mundo moderno, mas, mais exatamente, do ceticismo de Montaigne, para o período moderno de pensamento construtivo" ${ }^{\prime \prime 2}$.

9. Aqui não devemos confundir, dentre outros, dois sentidos do termo 'lógico'. De uma maneira, podemos dizer que toda argumentação que se pretenda ordenada por uma metodologia explicitável é 'lógica'. Nesse sentido, uma narrativa histórica documental certamente também é lógica. No entanto, não se deve confundir essa ordenação metodológica com uma teoria pressuposta que seja anterior à consulta dos documentos e, por sua anterioridade, seja denominada 'lógica' (no sentido que vimos em Maréchal) ou 'puramente lógica', em um sentido próximo a 'a priori'. Quando me refiro neste texto a um nível lógico de narrativa em oposição ao nível documental, estou utilizando somente esse segundo sentido do termo lógico. Isso porque, no primeiro sentido, o nível documental também pode ser dito lógico.

10. DESCARTES, R. Selections. Ed. R. M. Eaton. New York: Scribner's, 1927, p. $\mathrm{v}$ : "René Descartes, more than any other figure in the seventeenth century, marks the transition from Middle Ages to the modern world". Gilson cita a passagem de Eaton em The unity of philosopbical experience. 3rd ed. San Francisco: Ignatius Press, 1999 (1937), p. 99.

11. Idem, ibidem: "Commonplace as it may be, the statement contains a solid nucleus of historical truth (...)".

12. Idem, ibidem: "That statement needs, however, to be qualified. In the first place, Descartes marks the transition from the Renaissance, rather than from the Middle Ages, to the modern world. In the second place, he does not even 
Seguindo esse caminho, Gilson finalmente nos diz que "a longa lista de passagens do Discurso do Método que não são mais do que ecos dos Ensaios mostram claramente como Descartes estava em diálogo com o trabalho de Montaigne" ${ }^{\prime \prime 13}$. O interessante nessas 'qualificações' é que elas permitem a Gilson passar daquele plano histórico totalmente lógico, no qual Eaton opõe 'a Idade Média' ao 'mundo moderno' tomando como ponto de inflexão essa gigantesca figura de Descartes, para um plano histórico documental em que não podemos nem mesmo notar que Descartes e Montaigne se enfrentam, a não ser que façamos um estudo detalhado de todas aquelas passagens do Discurso do método que são, de fato, citações dos Ensaios. Em outras palavras, Gilson nos faz ir e vir, em poucas linhas, entre uma história lógica e uma história documental. O mais interessante, no entanto, é que ele aceita as duas como verdadeiras e como coexistentes. É como se a história, por um lado, tivesse um plano lógico e, por outro, um plano documental. E, é bom lembrar, Gilson levava esses dois planos muito a sério: quanto ao nível lógico da história, o ceticismo de fins do Renascimento "estava fadado a se seguir como conclusão necessária" das doutrinas escolásticas ${ }^{14}$; quanto ao seu nível documental, citemos que Gilson de fato faz uma minuciosa comparação entre o Discurso do método e os Ensaios na sua magistral edição do Discurso de Descartes ${ }^{15}$. Enfim, na narrativa histórica de Gilson, convivem - ao que parece, pacificamente, lado a lado - o nível lógico e o nível documental da história. Mas, resta ainda um elemento da história narrada por Gilson: os dois níveis parecem se comunicar de alguma maneira, pois, como vimos nos trechos citados, o fato de que há citações dos Ensaios no Discurso do método aponta para o diálogo que Descartes trava com Montaigne. Seria possível igualmente extrapolar esse exemplo e dizer que o fato

mark the transition from the whole Renaissance to the modern world, but, quite exactly, from the skepticism of Montaigne to the modern period of constructive thinking in philosophy".

13. Idem, p. 100: "The long list of passages of the Discourse on Method that are but an echo of the Essays, clearly shows how conversant Descartes was with the work of Montaigne".

14. Idem, p. 94: "The generalized scepticism of the Renaissance was bound to follow from such doctrines [a saber, as doutrinas escolásticas do século XIV] as their necessary conclusion".

15. Ver DESCARTES, R. Discours de la méthode. Texte et commentaire par Étienne Gilson. 6e éd. Paris: Vrin, 1987 (1925). 
de Descartes estar em diálogo com Montaigne aponta, em última instância, para a conclusão de que o mundo moderno (pretensamente inaugurado por Descartes) se opõe necessariamente à Idade Média (quiçá, encerrada, já no Renascimento, por Montaigne)? Seria a garantia da coexistência entre os níveis lógico e documental da história de Gilson o fato de que este último nos guia àquele primeiro? Antes de responder, vale a pena fazer um pequeno excurso que nos mostrará a atualidade do problema aqui abordado.

Longe de ser ultrapassada, a narrativa histórica de Gilson - na qual, como vimos, há uma constante passagem entre dois níveis de história, um lógico e outro documental - é ainda hoje largamente utilizada como padrão de narrativa histórica. Com efeito, em um número recente deste mesmo periódico, foi publicado o artigo "Afinal, para que serve a Filosofia Medieval?", de autoria de José Carlos Estêvão. Notemos, de início, que o caráter imediatamente polêmico do artigo estava não tanto em uma discussão sobre concepções distintas de história da filosofia, mas na defesa de que o estudo da filosofia medieval deve servir para algo, isto é, de que a narrativa da história da filosofia medieval deve ter uma serventia. Acredito que aquilo que estou denominando aqui de 'utilidade da história da filosofia' se aproxima bastante dessa exigência de uma 'serventia' da história da filosofia feita por Estêvão. Assim, em momento algum discordo de que a história da filosofia deva ter uma serventia ou uma utilidade, pois, caso contrário, como estabelecer um caminho ou uma metodologia para a narrativa histórica, sem termos um objetivo definido? E, no entanto, esse é o exato ponto em que me afasto do artigo de Estêvão, pois ali ele diz que se estuda "Filosofia Medieval para melhor compreender a Modernidade, ou antes, para entender a necessidade da Modernidade" ${ }^{116}$. A princípio, aquilo que Estêvão busca com a história da filosofia medieval não parece muito distinto daquilo que Rorty busca ou que nós aqui, baseados neste último, buscamos - ele procura compreender algo pela história, em especial, ele deseja compreender o que é a Modernidade pela história da filosofia medieval. O problema está na explicação que Estêvão propõe à sua própria formulação, pois para ele compreender a Modernidade não é compreender historicamente a

16. ESTÊVÃO, J. C. "Afinal, para que serve a Filosofia Medieval?". Cadernos de Filosofia Alemã, São Paulo, XVII, 2011, pp. 13-30, jan.-jun. 2011 (o trecho citado se encontra na p. 14). 
noção de 'Modernidade', mas estabelecer a necessidade de uma Modernidade enquanto elemento da história. Mas, se estamos falando em necessidade, adentramos claramente o campo da narrativa lógica da história, de maneira que o objetivo da história proposta por Estêvão está não no nível documental da história e, isso sim, no seu nível lógico. Essa Modernidade de Estêvão, que necessariamente se segue à Idade Média, é gêmea daquele ceticismo de Gilson, que necessariamente se segue às doutrinas escolásticas - ambos estão em um nível lógico da narrativa histórica.

No entanto, tal como ocorre em Gilson, essa afirmação de necessidade (relativa ao nível lógico da história) tem por base um interessante estudo histórico de diversos autores individuais e, para ser mais exato, do corpo documental formado pelas obras desses autores. Assim, a ida ao documento é, para o texto de Estêvão, imprescindível, pois ela própria é a base das afirmações de necessidade histórica portanto, o caso parece ser aqui totalmente distinto do que ocorria em Maréchal, onde a história em nada diz respeito à elaboração lógica do argumento filosófico. E, ainda assim, o artigo de Estêvão é sintomático da grande dificuldade de uma narrativa histórica ao modo de Gilson: ela pressupõe a própria conclusão! De fato, desde o início do artigo já está claro que a Filosofia Medieval estabelece a necessidade da Modernidade, sendo a ida aos documentos somente em pretensão um argumento, mas de fato um mero encaixe de documentos históricos em uma ordem (já preestabelecida, diga-se de passagem) que permita a reafirmação da tese inicial que, ademais, já estava de saída dada. Sendo assim, vemos que o historiador da filosofia ao modo de Gilson cai em petição de princípio ao pressupor a própria tese que ele pretende provar. No caso de Estêvão, se recorre aos documentos para provar que a Modernidade é necessária quando essa necessidade já está de saída estabelecida. Se voltarmos ao próprio Gilson, vemos que esse é exatamente o caminho que ele segue, pois estabelece desde o começo que Descartes abre o mundo moderno ao encerrar a Idade Média e, só em seguida, recorre aos textos filosóficos, para pretensamente provar algo que já estava de início afirmado.

Ora, daí fica claro como o próprio objetivo original de Estêvão se vê frustrado, uma vez que a história da filosofia medieval acabou não servindo para nada, pois se o fato que ela provaria - a necessidade da Modernidade - já está no início estabelecido, para que fazer história da filosofia? E a mesma pergunta valeria para a história, narrada por Gilson, da passagem da Idade Média para o mundo moderno: se 
a contraposição entre Descartes e Montaigne já está estabelecida antes do estudo minucioso do texto do Discurso do método em comparação aos Ensaios, para que fazer esse estudo? E, agora, podemos voltar àquela pergunta que fazíamos mais acima: como voltar do nível documental ao nível lógico da história em uma narrativa ao modo de Gilson? A resposta é fácil: não há como fazê-lo! Pois, como universalizamos um fato histórico - por definição, singular e irreproduzível? Para partir da afirmação "o início do Discurso do método é uma citação quase que literal dos Ensaios Montaigne" e chegar àquela outra "o mundo moderno se opõe à Idade Média", é preciso já pressupor que Descartes e Montaigne são, respectivamente, moderno e medieval. $\mathrm{O}$ problema é que tudo o que podemos fazer para compreender o lugar dos Ensaios de Montaigne na história da filosofia é, igualmente, ressaltar as remissões que ele faz a outros textos e assim por diante. Igualmente, de nada valeria dizer que "Descartes afirma que está fazendo algo novo, portanto ele rompe com a Idade Média", pois isso seria somente uma confusão entre a linguagem-objeto (no caso, o texto de Descartes em estudo) e a linguagem da narrativa histórica. Assim, no nível da narrativa histórica documental, do fato de Descartes afirmar "estou fazendo algo novo" se segue somente que "Descarte afirma estar fazendo algo novo", mas não que ele de fato esteja fazendo algo novo. Além disso, não podemos chegar àquela asserção geral sobre a oposição entre mundo moderno e Idade Média, ao dizer que há várias instâncias dessa oposição, pois o fato de Hobbes, em um texto, dizer que se opõe à universidade e o fato de Descartes, em outro, afirmar que se opõe às escolas são historicamente eventos individuais e, portanto, completamente distintos. Eles não possibilitam nenhuma generalização. Se, por outro lado, insistirmos em tomá-los como fatos idênticos (e, portanto, que permitiriam uma generalização), vemos a pobre história que terminaríamos por narrar, na qual todos os eventos são um único.

Dessa maneira, não há como pular de um certo momento desses fatos históricos individuais que lemos nos documentos para esse almejado e, vemos agora, inatingível nível lógico da história da filosofia. Por fim, vemos que aquele equilíbrio na narrativa histórica de Gilson não é senão aparente, pois o preço dele é que sempre a narrativa histórica em nível lógico antecede e inutiliza a narrativa histórica documental, se sobrepondo a ela. Se inserirmos um nível lógico na nossa narrativa histórica, não há alternativa: estamos, sem dúvida, pressupondo algo que não pode ser provado pelo estudo dos documentos. 
Assim, em última instância, recaímos irremediavelmente em uma narrativa ao modo de Maréchal e, portanto, a nossa história perde qualquer utilidade explicativa com respeito à determinação do significado das noções filosóficas, não sendo mais do que uma ferramenta que torna a exposição dessa nossa tese preconcebida mais palatável para o público.

Sendo assim, proponho: deixemos de lado essa oscilação tensa - que, como vimos, não se sustenta - entre o nível lógico e o nível documental da história. Devemos escolher um ou outro. Ora, tomar a posição de Maréchal é retirar à história da filosofia qualquer utilidade no que diz respeito à explicação das noções filosóficas, pois nesse caso ela seria somente uma maneira de expor uma tese já produzida por meios alheios à narrativa histórica. Portanto, se pretendemos fazer uma história que explique noções filosóficas, nos resta fazer a narrativa de uma história da filosofia exclusivamente documental, que lide unicamente com fatos singulares e, portanto, com textos. O preço que pagamos é a impossibilidade de recurso a qualquer generalização de nossas conclusões e, dessa maneira, o total abandono até mesmo de qualquer pretensão à narrativa da história em um nível lógico. Como veremos, entretanto, essa aparente perda é, antes, um ganho, porque ela nos libera para fazer o que Maréchal não podia, já que agora estamos em posição de estudar todos os documentos históricos acessíveis e a complexidade que obtivermos, longe de atrapalhar a exposição, nos permitirá compreender cada vez mais detalhadamente as noções filosóficas que nos interessam ${ }^{17}$.

17. Um modo de narrativa histórica que tenta escapar às críticas aqui formuladas é aquele esboçado por Alain de Libera em L'art des generalités: théories de l'abstraction. Paris: Aubier, 1999, pp. 6-9. Nesse começo de seu livro, de Libera argumenta que a história por ele narrada diz respeito antes à descontinuidade, a qual se manifesta historicamente na forma de diversas épistémés que surgem na medida em que o 'preenchimento' de uma série de invariantes estruturais se modifica. Essas invariantes estruturais, por sua vez, são lugares em um dispositivo em rede, de maneira que a mudança de preenchimento em um ponto da rede necessariamente afete o preenchimento de outro lugar. Ao que parece, para de Libera, cada modo distinto de preenchimento dessa rede estrutural constitui uma épistémé. O que ele quer dizer exatamente com isso é um problema que deixaremos em aberto. Por outro lado, vale a pena notar que essa concepção de história permite a ele defender que o objeto histórico que ele busca é "la mémoire: la mémoire matérielle, la mémoire inconscien- 


\section{Pars construens}

Surpreendentemente, um dos efeitos mais claros de qualquer concepção de história da filosofia que pressuponha um nível lógico de narrativa é o talento para excluir de tal narrativa, com a base nas pré-concepções estabelecidas nesse nível lógico, corpos textuais inteiros. Acima notamos o quanto Maréchal é explícito sobre a necessidade de 'simplificar' sua narrativa, mas o próprio Gilson afirma com segurança que "apesar dos seus grandes resultados em outros campos, o século XVI conta muito pouco no que diz respeito à própria história da filosofia"18 e isso simplesmente porque, por alguma razão (que certamente não é estabelecida em documentos textuais), para Gilson, a história da filosofia deve atentar, principalmente, para aqueles períodos, como o mundo moderno ou a Idade Média, em que houve um 'pensamento construtivo', distinto daquele ceticismo disseminado no século XVI. Um dos resultados mais dramáticos dessa concepção de história foi a exclusão quase que completa do gigantesco corpo de

te, la mémoire sans sujet, bref la mémoire des textes" (p. 8). Ora, como vemos, o importante para de Libera é antes uma 'memória', de maneira que o corpo textual da sua pesquisa só se forma na medida em que diz respeito a essa 'memória'. Assim, aquela tentativa de distinguir as várias épistémés singulares é em vão, pois todas elas terminam sendo englobadas pela 'memória' que, determinando a leitura dos textos, determina o próprio modo de acesso às épistémés. Daí que a história narrada por de Libera aponta somente aquela 'memória' que ele diz encontrar no texto, sem qualquer compromisso com uma interpretação não enviesada dos documentos. Um resultado marcante desse modo de narrativa pode ser visto no seu livro La querelle des universaux: de Platon à la fin du Moyen Age. Paris: Éditions du Seuil, 1996, onde a filosofia produzida do século $\mathrm{V}$ ao $\mathrm{XV}$ se transforma em uma épica batalha entre Platão e Aristóteles que, curiosamente, exclui qualquer influência de Agostinho sobre os autores. Notemos bem, a história narrada por de Libera simplesmente exclui Agostinho, aquele que é o autor mais citado nos textos filosóficos latinos durante esses mil anos ao lado de Aristóteles! Assim, nossa crítica vale também contra essa posição, uma vez que, ao recorrer a um nível lógico (que ele denomina 'estrutural'), de Libera se desvencilha de qualquer compromisso com uma narrativa histórica a partir do próprio documento. Também ele reaparece como continuador de Maréchal.

18. GILSON, The unity of philosopbical experience, p. 94: "Despite its great achievements in other fields, the sixteenth century counts for very little in the history of philosophy itself". 
estudos filosóficos produzidos nas universidades entre os séculos XVI e XVIII ${ }^{19}$, justificada simplesmente pelo fato de os mestres universitários desse período trabalharem com a produção de comentários aos autores dos séculos XIII e XIV (em particular, das obras de Tomás de Aquino, João Duns Escoto e Guilherme de Ockham). Ora, como vimos em Gilson, a 'Modernidade' se opõe à 'Idade Média' se seguindo necessariamente a ela, como Estêvão completa. Assim, não importa que Bartolomeu Mástrio e João Pôncio sejam contemporâneos de Descartes e Espinosa, pois estes últimos são modernos e aqueles primeiros não! Enfim, até mesmo o resultado cronológico da manutenção de um nível lógico na história é desastroso. Assim, como ademais já foi dito, abandonarmos qualquer pretensão de uma narrativa histórica em um nível lógico, mais do que um preço a pagar, é um ganho inestimável. Mas, deixados a sós com nossa história documental, vários problemas se nos impõem, os quais podem ser reduzidos às duas dificuldades principais formuladas a seguir:

(1) Se a nossa história dispensa qualquer meio (e, mais, qualquer exigência) de generalização, cada narrativa dirá respeito a um corpo reduzido de textos, uma vez que a leitura desse corpo exigirá atenção aos mínimos detalhes dos documentos, pois não são as generalidades que nos atraem e, sim, as idiossincrasias. Nesse caso, como selecionar o corpo sem recorrer a um itinerário lógico preconcebido? $\mathrm{Ou}$, para pôr o problema positivamente, como selecionar o corpo de textos unicamente a partir dos próprios documentos?

(2) Estabelecido um corpo de textos, decerto é preciso fazer uma leitura atenta de cada texto individualmente com o fim de compreender a argumentação nele exposta. Ainda assim, isso é somente um primeiro passo rumo à narrativa histórica, já que esta última só terá lugar quando pudermos relacionar entre si os diversos textos que formam nosso corpo documental. Ora, como relacionar os textos entre si sem recorrer a generalizações? Ou melhor, como relacionar os documentos entre si unicamente a partir dos próprios documentos?

Comecemos pela segunda questão, pois a sua resposta nos indicará o caminho para a solução da primeira. O que temos que notar de saída é que, não desejando recorrer a conceitos gerais ou universais

19. Para um estudo introdutório sobre os autores universitários desse período, ver SCHMUTZ, J. "L'héritage des subtils: cartographie du scotisme de l'âge classique". Les études pbilosopbique 60 (2002), pp. 51-81. 
preconcebidos, o que nos resta são os próprios documentos estudados que, no caso da história da filosofia, não são senão textos particulares. Porém, já aqui, enfrentamos o sério problema do acesso aos textos, uma vez que a leitura que deles fazemos depende, antes de tudo, da maneira como eles são estabelecidos. Assim, simplesmente para estabelecer o nosso documento, devemos lidar com diversas questões ligadas: à língua em que o texto deve ser lido por nós (pois lembremos que nem sempre é o caso de ler o texto na sua língua original - por exemplo, se queremos estudar a recepção dos Analectos de Confúcio na Europa do século XVII, é mais útil ler sua tradução latina do que o original chinês e, por outro lado, se quisermos compreender o próprio poema de Parmênides teremos, sem dúvidas, que estudá-lo em grego); à própria metodologia de edição crítica, que envolve todos os problemas típicos de qualquer atividade edótica, nos pondo, por vezes, em face de dúvidas complexas (seria mais interessante, no trabalho de edição crítica das obras de Aristóteles, ter como um fim, ainda que inatingível, chegar à reprodução fiel do original tal como o autor o escreveu, ou estabelecer criticamente a versão do texto que mais circulou, mesmo que ela seja distinta do original?); bem como a muitos outros problemas que surgem esporadicamente na consideração de um texto em particular.

Pois bem, estabelecido clara e diligentemente o texto a ser lido de acordo com o nosso interesse de estudo, o problema agora é ler o próprio texto. No entanto, como não possuímos nenhuma elaboração universal ou lógica pré-concebida, não podemos saber o que é dito, por exemplo, no Discurso do método a não ser que o leiamos. Em outras palavras, eu não leio o Discurso do método porque ele rompe com a Idade Média ou com o Renascimento e nem porque ele inaugura o mundo moderno, mas simplesmente leio o Discurso do método. Agora, como eu cheguei até ele? Isto é, por que seria interessante ler esse texto ainda que ele não inaugure um período ou encerre algum outro? Ora, simplesmente porque alguma noção filosófica que buscamos compreender é utilizada no Discurso do método. Voltando ao início, se quisermos, como Rorty, compreender o que é mind (e aceitarmos que âme pode ser tomada como uma palavra correlata em francês para o inglês mind), então se torna muito interessante para nós compreender como a palavra âme é utilizada no Discurso do método. E podemos fazê-lo pelo estudo cuidadoso dos argumentos formulados nesse documento que envolvam o termo âme, de maneira a que o significado de 'âme' aceito neste texto em particular possa ser determinado pelo modo como 
esse termo é utilizado, ou melhor, pela minuciosa descrição da maneira como essa palavra individual se relaciona com outras no texto em estudo. Feito isso, teremos realizado um estudo acurado da noção de âme tal como a encontramos no Discurso do método. E, não obstante, isso não basta para o estabelecimento de uma história dessa noção e, portanto, não é o suficiente para a sua compreensão, a que almejamos.

Para, a partir desse estudo inicial, escrevermos uma história é necessário mostrarmos como o uso da noção de 'âme' no texto já estudado pode ser comparado a outros usos dessa noção em outros documentos, atentando para o que há de semelhante e de distinto entre esses usos, isto é, para as diferentes maneiras nas quais, em cada texto, o termo em estudo se relaciona a outros termos ${ }^{20}$. No presente caso, estamos com sorte, pois há uma obra publicada em uma data muito próxima à do Discurso do método, na qual o termo 'âme' é utilizado de maneira particularmente parecida com o seu uso no Discurso do método - por exemplo, no que diz respeito à relação estabelecida, nos textos, entre as palavras 'âme' e 'penser'. Esse texto possui uma versão em latim, Meditationes de prima pbilosopbia, e outra francesa, Méditations métaphysique (o que nos faria, decerto, permanecer um tempo na consideração sobre o uso do termo âme como correlato do latim mens em alguns trechos dos textos). Agora, o interessante no uso conjunto desses dois textos é que eles podem ser relacionados de uma maneira bem característica, já que muitos documentos (inclusive, nesse caso, as próprias obras) nos fornecem informações que tornam atualmente unânime a atribuição de ambos ao mesmo autor, a saber, René Descartes. Porém, nem sempre temos essa sorte... O corpo de textos anônimos a que temos acesso atualmente é gigantesco e, não obstante, podemos produzir estudos filosóficos bem interessantes com base neles ${ }^{21}$. Com isso eu quero somente lembrar que a autoria, isto é, a atribuição do nome de uma pessoa a uma obra como determinação de seu autor não é o principal na história que estamos fazendo. Sem

20. Lembremos como Foucault aponta, em Les mots et les choses: une archéologie des sciences bumaines. Paris: Gallimard, 1966, pp. 36-7, para o fato de que o uso das mesmas expressões por autores distintos não expõe necessariamente um mesmo uso dos termos, sendo antes frequentemente sinal da atribuição de significados distintos, em cada caso, a esses mesmos termos.

21. É o caso de GIELE, M., VAN STEENBERGHEN, F., BAZÁN, B. (ed.). Trois Commentaires Anonymes surle Traitéde l'Ame d'Aristote. Louvain - Paris: Publications Universitaires - Béatrice-Nauwelaerts, 1971. 
dúvida, muitas vezes poder atribuir vários textos a um único autor nos ajuda a compreender a relação e a sucessão cronológica desses textos, em especial no caso de um autor como Descartes, cuja biografia é detalhadamente estabelecida a partir de diversos documentos. Em outros casos, porém, a atribuição da mesma autoria a vários textos não faz mais do que apontar de maneira bem obscura que provavelmente há alguma relação entre eles. De fato, frequentemente é mais fácil determinar a autoria do texto a partir do estudo desse próprio texto com relação a algum outro, do que compreender o texto a partir da atribuição a um autor. Para dar um exemplo, podemos pensar no caso do Sobre o princípio das coisas, atribuído desde o século XVII a João Duns Escoto. Com efeito, essa atribuição atrapalhava em muito a compreensão tanto do Sobre o princípio das coisas como dos outros textos atribuídos a Duns Escoto. A solução foi argumentar, a partir de diversos documentos (inclusive ele próprio), que esse texto em particular deveria ser atribuído a outro autor, a saber, Vital de Furno. Como vemos, não foi a autoria que determinou a interpretação do texto. Pelo contrário, a dificuldade de fazer o Sobre o princípio das coisas e o restante dos Opera omnia atribuídos a Duns Escoto concordarem foi tamanha, que se preferiu dar um maior peso a documentos e leituras desses documentos que permitissem atribuir aquele texto a um autor com cujas obras o Sobre o princípio das coisas parece concordar mais ${ }^{22}$. Ou seja, uma comparação puramente textual determina a autoria e não o contrário. Dessa maneira, ainda que inclua a referência a autores, a nossa história é antes de tudo uma história de textos alguns dos quais podem ser agrupados sob determinadas rubricas a que denominamos 'autores', enquanto outros não podem. Nesse caso, a comparação entre o uso de um mesmo termo em textos atribuídos a autores diferentes é, em geral, tida por mais difícil, porque é esperado que a diferença no uso de um mesmo termo em dois textos de autores distintos seja maior do que aquela que ocorre entre dois textos de um mesmo autor. Porém, como o caso de Duns Escoto e Vital de Furno nos mostra, não há nenhuma necessidade nessa expectativa.

Nesse ponto começamos a perceber que a única maneira pela qual podemos relacionar dois textos distintos na nossa história é pela

22. Para uma introdução a toda a discussão sobre a autoria do Sobre o princípio das coisas, ver LYNCH, J. E. Theory of knowledge of Vital du Four. St. Bonaventure: The Franciscan Institute, 1972, pp. 1-10. 
remissão que um texto faça a um outro e, portanto, há que se organizar cronologicamente os documentos que compõem essa história, pois um documento só pode remeter textualmente a um outro documento que já esteja acessível quando da sua produção, ou seja, a um outro documento que lhe seja anterior cronologicamente ${ }^{23}$. Porém, essa remissão não pode ser algo como: "Descartes se opõe à Idade Média, portanto ele deve estar se referindo aqui a Tomás de Aquino", pois essas teses gerais não se sustentam nos textos, como vimos longamente, e nós não temos nada senão textos. Dessa maneira, essas remissões textuais devem ser: citações claras (com referência explícita ou não ao texto de onde ela é retirada), o uso de um mesmo termo (como vimos acima, no caso do termo âme) e demais ocorrências desse tipo. Por outro lado, a mera referência a um nome não é evidência de uma remissão direta. Por exemplo, quando Hobbes, ao fim do capítulo 1 do seu Leviatã, se refere aos 'Texts of Aristotle' lidos nas universidades, ele está de fato remetendo a algum texto atribuído em sua época a Aristóteles? Se sim, em que edição ou cópia manuscrita e língua ele o leu? Se não, que texto lido por ele poderia ter servido de fundamento para essa referência ao nome 'Aristóteles'? Como vemos, a referência a um nome não nos diz nada sobre as remissões textuais e nossa história se compõe somente destas últimas tal como elas podem ser organizadas cronologicamente. Assim, nos propomos aqui a seguir uma cronologia - e isso, porque as relações históricas são sempre pensadas em termos de remissões entre textos, de maneira que precisamos tomar o texto que apresenta a remissão como posterior àquele a que ele remete. Em outras palavras, as remissões intertextuais encontradas em nossa pesquisa nos permitem o estabelecimento de uma cronologia.

Portanto, e para tomar uma expressão emprestada de Michel Foucault, a nossa história é uma série de eventos ${ }^{24}$ maximamente com-

23. Isto é, na nossa história não há espaço para que Anselmo se guarde contra uma crítica de Tomás de Aquino ou de Kant - como Jean-Luc Marion propõe que ocorra em "L'argument relève-t-il de l'ontologie?". Archivio di Filosofia 58 (1990), p. 53 - ou para que possamos ler os autores sem nos preocuparmos com o fato de que eles são de épocas diferentes da nossa como Paul Ricoeur afirma fazer, em La mémoire, l'bistoire, l'oubli. Paris: Éditions du Seuil, 2000, p. iii.

24. Aqui me refiro não ao Michel Foucault de Les mots et les choses, que inspira Alain de Libera (ver nota 17) ao buscar aquilo que está sob ou para além do discurso (pois isso equivale à busca de um nível lógico da história a partir do 
plexificável, isto é, cujos elementos e cuja formulação das remissões entre seus elementos pode sempre ser ainda mais detalhada do que já era. Dessa maneira, essa é uma história que pretende compor uma sucessão cronológica entre eventos e, como já está claro nesse ponto, os eventos de uma história da filosofia não são senão os textos de interesse filosófico - isto é, aqueles textos que em alguma medida contribuem para a narrativa da história que nos levará à compreensão de alguma noção filosófica que pretendemos melhor conhecer. Agora, todos esses eventos só formam uma série porque eles se relacionam por meio de remissões, pelas quais os textos tidos como posteriores na série cronológica (uma vez que eles fazem a citação) remetem a textos tidos como anteriores nessa mesma série (dado que eles são os documentos citados). Assim, a única maneira de relacionar os eventos daquela série é o estabelecimento de relações de remissão entre os textos e, portanto, é pela explicação do débito de cada evento na série para com os outro eventos, tal que estes sejam anteriores àqueles. Em outras palavras, a série cronológica só pode ser estabelecida na medida em que for possível apontar a que outros textos cada um dos textos remete. A essa relação, pela qual um texto posterior na série remete a outro anterior, darei o nome de influência, tomando por base os estudos de crítica literária de Harold Bloom $^{25}$. Dessa maneira, quando dizemos que, em fins do século XIII, uma Questão disputada sobre a vontade atribuída a Gonçalvo de Espanha apresenta diversas citações de uma outra Questão disputada sobre o mesmo tema atribuída a João, o Sábio ${ }^{26}$, podemos igualmente dizer

seu nível documental, o que vimos ser impraticável), mas àquele de L'ordre $d u$ discours. Paris: Gallimard, 1971, p. 55 e sg., que pretende compreender cada evento unicamente como inserido em uma série de eventos, sem apontar qualquer substrato arqueológico abaixo da própria história.

25. A importância de Harold Bloom está principalmente em chamar a atenção para o fato de que a influência percebida em uma obra literária diz respeito unicamente ao próprio texto e não ao autor: "Influence anxiety, in literature, need not be an effect in the writer who arrives late in a tradition. It always is anxiety achieved in a literary work, whether or not its author ever felt it". BLOOM, H. The Anatomy of Influence. Literature as a Way of Life. New Haven Lodon: Yale University Press, 2011, p. 6.

26. Sobre as remissões mútuas nas obras de Gonçalvo de Espanha e João, o Sábio, ver DUMONT, S. D. "Did Duns Scotus Change His Mind on the Will?". In: 
que aquele texto de Gonçalvo de Espanha sofre influência deste texto de João, o Sábio ${ }^{27}$.

Enfim, temos aqui respondida a nossa segunda pergunta: como relacionar os documentos entre si unicamente a partir dos próprios documentos? Podemos fazê-lo organizando os textos de interesse filosófico para a nossa narrativa histórica em uma série cronológica de eventos, formada a partir do estabelecimento das relações de influência entre os textos, tal como propusemos acima. Com isso, não será muito difícil responder àquela nossa primeira pergunta, a saber: como selecionar o corpo de textos unicamente a partir dos próprios documentos? Na nossa narrativa histórica, a leitura de cada documento nos remete a outros e, portanto, os documentos a que o texto em estudo remete mais claramente são os principais candidatos a também servirem como documentos em nossa narrativa histórica. Ou seja, a própria leitura de um documento aponta para os outros documentos que poderão compor a história que buscamos narrar com o intuito de esclarecer uma determinada noção filosófica. Portanto, aquilo que nos aponta os componentes da série cronológica de eventos são as próprias relações de influência. Seguindo esse caminho, podemos estabelecer um certo conjunto principal de obras, determinado a partir do estudo dos próprios textos, cuja leitura seja mais urgente para o estabelecimento da narrativa histórica. Por exemplo, ao lermos o início da Suma de Henrique de Gand, na qual ele discute o que é o conhecimento, são notáveis as várias vezes em que ele cita diretamente obras de Agostinho, Cícero e do Aristóteles latino, de maneira que a influência desses textos sobre Henrique se torna marcantemente patente. Assim, está claro que o retorno aos textos desses autores que este último cita é urgente, caso desejemos compreender a concepção de conhecimento em fins do século XIII pela narrativa da sua história. Por outro lado, em algumas passagens, Henrique se utiliza do termo latino illabi de uma maneira muito parecida com o uso desse mesmo termo que encontramos n'Os dogmas

AERTSEN, J.A., EMERY, Jr. K., SPEER, A. (eds.). Nacb der Verurteilung von 1277. Berlin: de Gruyter, 2001, pp. 774-6.

27. Por metonímia, poderíamos até afirmar simplesmente que Gonçalvo de Espanha sofre influência de João, o Sábio, mas, ao fazê-lo, sempre correremos o risco de nos enredarmos nas confusões provocadas pelo uso de figuras de linguagem em discussões filosóficas. 
eclesiásticos de Genádio de Marselha ${ }^{28}$. Podemos dizer que, por sua citação ser um tanto esporádica no texto de Henrique, a obra de Genádio exerce menos influência sobre a Suma do que, digamos, o Sobre a trindade de Agostinho. Dessa maneira, sem dúvida, a leitura desta última obra é mais urgente na nossa narrativa histórica; e, no entanto, o texto de Genádio não deve ser excluído. Pelo contrário, por ser citado em momentos centrais do trabalho de Henrique, tão logo seja possível, ele também deve ser incluído em nossa narrativa, de modo a aumentar a complexidade da série de eventos narrada e, assim, a complexidade da nossa própria compreensão da noção de 'conhecimento' em fins do século XIII. Seguindo esse caminho, devemos avançar pelo estudo de todas as influências do texto estudado, ainda que elas sejam cada vez mais tênues.

Dito isso, vemos que não há uma seleção canônica de textos relevantes para cada narrativa histórica, porque os eventos considerados em cada série dependerão do objetivo que possuímos com o estabelecimento daquela série. Assim, o estudo cuidadoso daquelas remissões mútuas entre os textos de Gonçalvo de Espanha e João, o Sábio, podem ser um elemento de suma importância em uma narrativa histórica elaborada com o intuito de se compreender a noção de 'vontade' em fins do século XIII e início do XIV ${ }^{29}$, porém ela não será tão relevante quando tivermos por objetivo compreender historicamente o que se tomava por 'ciência' nessa mesma época. Portanto, podemos dizer, para responder àquela primeira pergunta, que a seleção do corpo de textos a serem considerados em uma narrativa histórica deve ocorrer pela consideração das relações de influência que se podem encontrar única e exclusivamente nos próprios textos estudados, da maneira como viemos descrevendo pausadamente. Essa seleção não será fixa em dois sentidos: primeiramente, porque ela poderá ser sempre mais complexificada, nos levando a uma compreensão cada vez mais completa da noção filosófica que pretendemos compreender pela nossa narrativa histórica; e, em segundo lugar, porque cada narrativa,

28. Sobre o uso do termo illabi no início da Suma de Henrique de Gand como uma referência a'Os dogmas eclesiásticos, ver EMERY JR., K.. "The Image of God Deep in the Mind: the Continuity of Cognition according to Henry of Ghent". In: AERTSEN, J.A., EMERY, Jr. K., SPEER, A. (eds.). Nach der Verurteilung von 1277. Berlin: de Gruyter, 2001, p. 79.

29. Ver nota 26, acima. 
dependendo do seu objetivo, nos guiará em direção a um certo corpo textual que caracterizará aquela narrativa. Voltemos a Paul Vignaux, pois é preciso deixar ver a diversidade rebelde!

\section{Coda}

Uma última palavra sobre o que proponho aqui. Em primeiro lugar, não afirmo que a concepção de história que proponho na segunda parte do artigo seja 'verdadeira' em oposição às outras que critico na primeira e que seriam 'falsas'. Não possuo de maneira alguma essa presunção. Também, decerto, não proponho que abandonemos certas maneiras de falar sobre a história, mas somente que tenhamos claro o que queremos dizer quando utilizamos cada expressão em uma narrativa histórica, para não corrermos o risco de incorrer em confusões desnecessárias - já nos bastam os problemas que surgem na própria elaboração da narrativa! Assim, não digo que termos como 'Modernidade' ou 'Idade Média' sejam completamente inúteis, pois se lhes for dado um significado bem simples (como, por exemplo, uma extensão cronológica precisa) eles podem servir muito bem para a organização didática de grades curriculares. Por outro lado, utilizados em frases como "Descartes inaugura a Modernidade e encerra a Idade Média" eles levam a confusões sem fim. Portanto, o nosso problema aqui não diz respeito à verdade ou falsidade de certa narrativa histórica, mas à sua utilidade. Afirmo que, ao estabelecermos o objetivo de compreender certas noções filosóficas pela narrativa histórica do seu desenvolvimento, precisamos escolher uma história que nos sirva para tanto, isto é, que de fato tenha essa utilidade. Como vimos acima, o único modo de explicar um conceito historicamente é pela narrativa de uma história estritamente documental ${ }^{30}$.

30. Acrescento que vários dos temas abordados aqui mereceriam um tratamento à parte para que fossem corretamente expostos. Em particular, três elementos deste artigo deveriam ser cuidadosamente elaborados: (i) o que se está tomando aqui por 'termo' ou 'noção filosófica'; (ii) a formulação e justificação das metodologias de estabelecimento e de leitura dos textos; e (iii) a viabilidade de se tomar um texto por um evento histórico. Esses três itens deveriam ser cuidadosamente considerados para que nossa tese fosse suficientemente desenvolvida. 


\section{Referências bibliográficas}

BLOOM, H. The Anatomy of Influence. Literature as a Way of Life. New Haven - Lodon: Yale University Press, 2011.

DESCARTES, R. Selections. Ed. R. M. Eaton. New York: Scribner's, 1927. Discours de la méthode. Texte et commentaire par Étienne Gilson. 6e éd. Paris: Vrin, 1987 (1925).

DUHEM, P. Sauver les apparences: sur la notion de théorie physique de Platon à Galilée. 2e éd. Paris: Vrin, 2003 (1908).

DUMONT, S. D. "Did Duns Scotus Change His Mind on the Will?". In: AERTSEN, J.A., EMERY, Jr. K., SPEER, A. (eds.). Nacb der Verurteilung von 1277. Berlin: de Gruyter, 2001, pp. 719-94.

EMERY JR., K.. "The Image of God Deep in the Mind: the Continuity of Cognition according to Henry of Ghent". In: AERTSEN, J.A., EMERY, Jr. K., SPEER, A. (eds.). Nacb der Verurteilung von 1277. Berlin: de Gruyter, 2001, pp. 59-124.

ESTÊVÃO, J. C. "Afinal, para que serve a Filosofia Medieval?". Cadernos de Filosofia Alemã, São Paulo, XVII, 2011, pp. 13-30, jan.-jun. 2011.

FEYERABEND, P. Against method. 4th ed. London-New York: Verso, 2010 (1975).

FOUCAULT, M. Les mots et les choses: une archéologie des sciences bumaines. Paris: Gallimard, 1966. L'ordre du discours. Paris: Gallimard, 1971.

GIELE, M., VAN STEENBERGHEN, F., BAZÁN, B. (ed.). Trois Commentaires Anonymes sur le Traité de l'Ame d'Aristote. Louvain - Paris: Publications Universitaires - Béatrice-Nauwelaerts, 1971.

GILSON, É. The unity of philosopbical experience. 3rd ed. San Francisco: Ignatius Press, 1999 (1937).

KUHN, T. S. The structure of scientific revolutions. 4th ed. Chicago: The University of Chicago Press, 2012 (1962).

LAKATOS, I. "History of science and its rational reconstructions". PSA: Proceedings of the Biennal Meeting of the Pbilosopby of Science Association (1970), pp. 91-136.

LIBERA, A. de. La querelle des universaux: de Platon à la fin du Moyen Age. Paris: Éditions du Seuil, 1996. L'art des generalités: théories de l'abstraction. Paris: Aubier, 1999.

LYNCH, J. E. Theory of knowledge of Vital du Four. St. Bonaventure: The Franciscan Institute, 1972. 
MARÉCHAL, J. Le point de départ de la métaphysique: leçons sur le développement bistorique et théorique du problème de la connaissance. Cahier I. De l'Antiquité à la fin du Moyen Age: La Critique Ancienne de la Connaissance. 2e éd. Bruges: Charles Beyart, 1927

MARION, J.-L. "L'argument relève-t-il de l'ontologie?". Arcbivio di Filosofia 58 (1990), pp. 43-69.

RICOEUR, P. La mémoire, l'bistoire, l'oubli. Paris: Éditions du Seuil, 2000.

RORTY, R. Philosophy and the Mirror of Nature. $2^{\text {nd }}$ ed. Princeton: Princeton University Press, 2009 (1979).

SCHMUTZ, J. "L'héritage des subtils: cartographie du scotisme de l'âge classique". Les études pbilosopbique 60 (2002), pp. 51-81.

VIGNAUX, P. Pbilosopbie au Moyen Age. Albeuve: Castella, 1987. 
